\title{
PELATIHAN TEKNIK PRESENTASI MENGGUNAKAN POWERPOINT PADA ANAK USIA PENDIDIKAN DASAR DI LINGKUNGAN MASJID AL MU'MINUN RW-12 KELURAHAN LOWOKWARU KOTA MALANG
}

\author{
M. Noor Hidayat ${ }^{1}$, Ferdian $\mathrm{R}^{4}$, Irwan $\mathrm{HE}^{3}$, M. Fahmi $\mathrm{H}^{5}$, Rohmanita $\mathrm{D}^{6}$ \\ Jurusan Teknik Elektro, Program Studi Teknik Listrik, Politeknik Negeri Malang \\ e-mail: moh.noor@polinema.ac.id ${ }^{1}$
}

\begin{abstract}
Microsoft Office Power Point Training for Elementary School-aged Children in the Neighborhood of the Al Mu'minun Mosque RW-12 in Lowokwaru Village, Malang City, provides additional skills and motivation for elementary and middle school children to have the ability to operate and to use Microsoft Office Power Point software (MS Power Point). With the additional knowledge and expertise, these children are expected to be able to overcome problems related to their school assignments.
\end{abstract}

Keywords: the Al Mu'minun Mosque, elementary and middle school children, MS Power Point

\section{PENDAhuluan}

\subsection{Latar Belakang}

Wilayah sekitar Masjid Al Mu'minun RW-12 Kelurahan Lowokwaru Kota Malang adalah pemukiman padat penduduk. Mayoritas masyarakat di wilayah bekerja di sektor swasta, seperti membuat kue atau makanan ringan, membuka toko kecil di rumah untuk berjualan ataupun membuka usaha menjahit/bordir. Banyak di antara keluarga-keluarga tersebut yang memiliki anak pada usia pendidikan dasar (SD sampai SMP), yakni dengan rentang usia antara 7 tahun sampai 15 tahun.

Seperti kita ketahui bersama, pada saat ini, metode pembelajaran yang diterapkan pada level pendidikan dasar telah banyak memanfaatkan komputer dan perangkat lunak pendukung untuk menunjang proses belajar mengajar di sekolah. Di samping itu, mereka harus mempresentasikan hasil kerja mereka secara elektronis dengan menggunakan software presentasi.

Berdasarkan kedua kondisi di atas, maka dapat diambil suatu peluang untuk dapat melaksanakan pengabdian pada masyarakat. Pengabdian pada masyarakat tersebut berbentuk pelatihan Teknik presentasi dan pengoperasian Microsoft Office PowerPoint (MS PowerPoint) pada anak-anak usia pendidikan dasar, dengan harapan mereka dapat mengenal dan memperoleh pengetahuan di dalam mengoperasikan program komputer berkaitan dengan software untuk presentasi. Sehingga akan mempermudah mereka di dalam mengikuti kegiatan belajar di sekolah dan dalam menyelesaikan tugas pekerjaan rumah.

\subsection{Tujuan Kegiatan}

Tujuan dari kegiatan pengabdian kepada masyarakat ini adalah untuk:

1. Memberikan tambahan pengetahuan dan keterampilan Pelatihan Microsoft Office Power Point pada Anak Usia Pendidikan Dasar di Lingkungan Masjid Al Mu'minun RW-12 Kelurahan Lowokwaru Kota Malang.

2. Memotivasi masyarakat, khususnya anak-anak usia SD-SMP di wilayah sekitar Masjid Al Mu'minun RW-12 Kelurahan Lowokwaru Kota Malang untuk mengembangkan potensi mereka terutama di software presentasi

\section{TINJAUAN PUSTAKA}

\subsection{Microsoft Power Point}

Microsoft Power Point adalah aplikasi presentasi paling popular yang dipakai duntuk melakukan presentasi, baik di bidang akademik maupun bisnis. Kelebihan dari software ini adalah bahwa setiap halaman baru yang kosong dapat diisi dengan beragam pilihan desain. Di samping itu, Power Point mempunyai banyak fitur untuk membantu kita membuat presentasi dengan cepat.

Ada beberapa software lain dalam presentasi, di antaranya adalah Keynote milik Apple dan Google Slides milik Google tetapi hanya sedikit saja aplikasi yang digunakan seumum Power Point.

\subsection{Membuat Presentasi PowerPoint Secara Cepat}

Ada beberapa tips yang dapat dilakukan untuk membuat presentasi secara cepat tanpa mengorbankan kualitas, di antaranya adalah [1]:

a. Gunakan Tema yang Sudah Disertakan

Power Point menyediakan banyak ide bagi slide presentasi sehingga dapat menghemat waktu ketimbang harus membuat dari awal.

b. Manfaatkan Layout yang Sudah Disertakan

Layout-layout ini merupakan cetak biru desain slide. Kebanyakan tema mempunyai layout-layoutnya masing-masing dan sudah menyertakan placeholder khusus untuk teks, gambar, video, dan masih banyak lagi.

c. Gunakan Kembali Elemen-elemen Kunci

Bila suatu grafik atau gambar sudah dibuat, maka akan bias di-copy lagi grafik tersebut ke halaman lain dan tinggal merubah data tabelnya saja, tidak perlu membuat baru lagi.

d. Merencanakan Isi Lebih Dulu dan Desain Kemudian 
Sebelum membuka PowerPoint, putuskan dulu apa yang ingin disampaikan dalam presentasi. Presentasi akan cepat dibuat kalau anda mau mendahulukan isi.

e. Slide yang Efektif

Tidak perlu memasukkan semua yang ingin disampaikan ke dalam PowerPoint. Slide itu hanya bantuan visual untuk mendukung presentasi anda, bukan berbicara untuk anda. Dengan jumlah slide yang lebih sedikit, maka akan menghemat waktu.

\subsection{Membuat File Baru PowerPoint}

Langkah-langkah untuk membuat slide presentasi baru dalam PowerPoint dapat dilakukan mengikuti langkah-langkah berikut [2]:

\section{Klik Tombol Microsoft Office , lalu klik} Baru.

2. Di bawah Templat, klik Tema yang diinstal. Saat Anda mengklik setiap tema, PowerPoint memperlihatkan pratinjau di sisi kanan.

3. Saat Anda menemukan yang Anda inginkan, klik buat di bagian bawah jendela.

\section{Untuk Menyisipkan slide baru}

- Di tab Beranda, klik bagian bawah Slide Baru, lalu pilih satu tata letak slide.

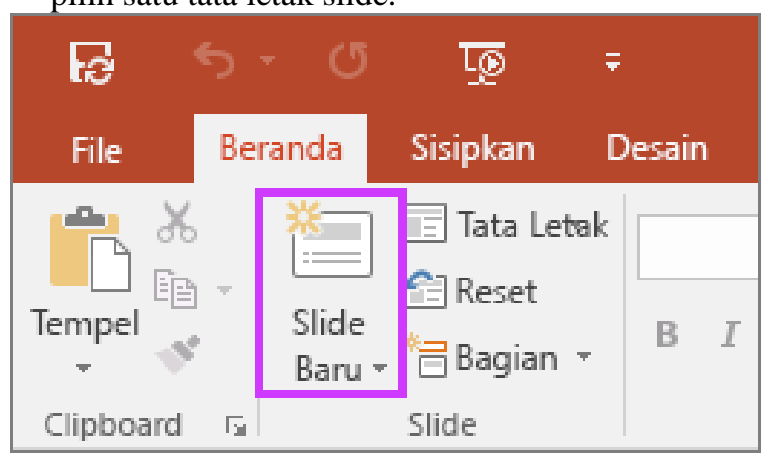

\subsection{Menyimpan presentasi}

1. Klik Tombol Microsoft Office , dan lalu klik Simpan.

2. Dalam kotak Nama file, ketikkan nama presentasi Anda, kemudian pilih Simpan. Untuk Menyimpan pekerjaan Anda saat Anda masuk. Tekan Ctrl + S sering.

\subsection{Menambahkan teks dan gambar}

Klik tempat penampung teks, dan mulailah mengetik.

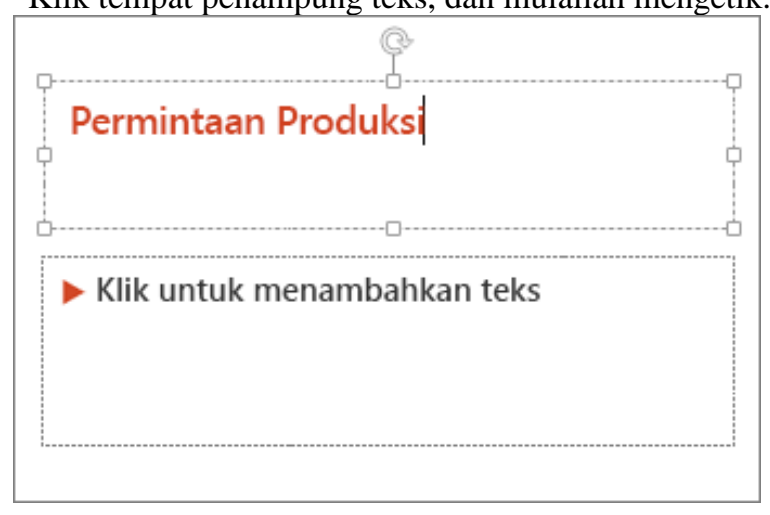

\section{Memformat teks}

1. Pilih teks.

2. Di bawah Alat Menggambar, pilih Format.

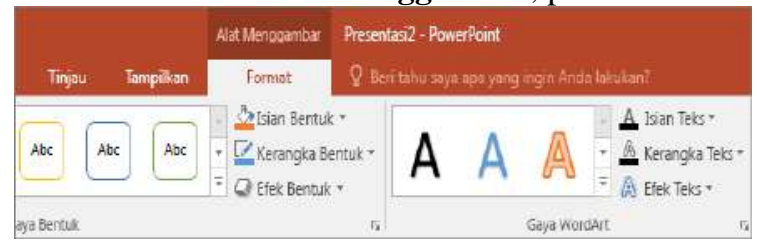

Lakukan salah satu hal berikut ini:

- Untuk mengubah warna teks Anda, pilih Isian Teks, lalu pilih sebuah warna.

- Untuk mengubah warna kerangka bentuk teks Anda, pilih Kerangka Teks, lalu pilih sebuah warna.

- Untuk menerapkan bayangan, pantulan, cahaya, kemiringan, rotasi 3D, transformasi, pilih Efek Teks, lalu pilih efek yang Anda inginkan.

\section{Untuk menambahkan gambar}

1. Pada tab sisipkan, pilih gambar.

2. Telusuri gambar yang Anda inginkan, dan lalu pilih sisipkan.

\subsection{Menambahkan catatan pembicara}

Slide yang terbaik ketika Anda tidak menjejalkan terlalu banyak informasi. Anda bisa menaruh berguna fakta dan catatan catatan pembicara, dan rujuk mereka saat Anda menyajikan. Dalam tampilan Normal, panel catatan terletak tepat di bawah jendela tampilan slide.

1. Pada tab Tampilan, dalam grup Tampilan

Presentasi, klik Normal.

2. Klik di dalam panel Catatan di bawah slide tersebut, dan ketikkan catatan Anda.

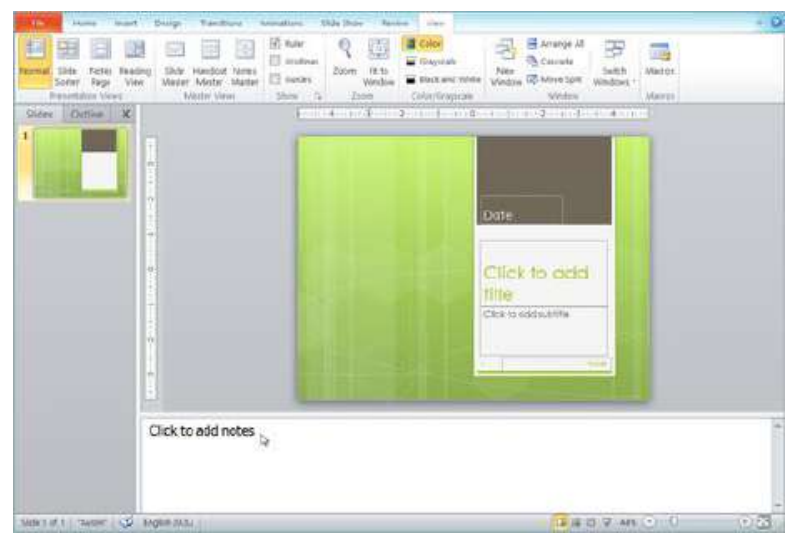

\subsection{Menyampaikan presentasi}

Pada tab Peragaan Slide, lakukan salah satu hal berikut ini:

- Untuk memulai presentasi pada slide pertama, di grup Mulai Peragaan Slide, klik Dari Awal.

- Jika Anda tidak berada di slide pertama dan Anda ingin memulai dari posisi Anda, klik Dari Slide Saat Ini.

\subsection{Keluar dari tampilan Peragaan Slide}

Untuk keluar dari tampilan Peragaan Slide kapan saja, pada keyboard, tekan Esc. 


\section{METODE}

\subsection{Khalayak Sasaran}

Pelatihan ini ditujukan untuk anak usia pendidikan dasar (SD-SMP) di lingkungan Masjid Al Mu'minun yang terletak di wilayah RW-12 Kelurahan Lowokwaru Kecamatan Lowokwaru Kota Malang.

\subsection{Metode Pelaksanaan PKM}

Untuk menentukan metode PKM maka di program pengabdian masyarakat ini, harus diketahui tingkat pendidikan masyarakat di wilayah sekitar Masjid Al Mu'minun RW-12 Kelurahan Lowokwaru Kota Malang, guna memenuhi sasaran yang tepat. Dengan mengetahui rata-rata tingkat pendidikan tersebut, maka materi yang akan diberikan dapat disesuaikan untuk menunjang kegiatan Pengabdian Kepada Masyarakat ini.

Kegiatan Pelatihan Microsoft Office Power Point pada Anak Usia Pendidikan Dasar di Lingkungan Masjid Al Mu'minun RW-12 Kelurahan Lowokwaru Kota Malang ini, dilaksanakan dengan metode langsung praktek, yaitu:

1. Pengenalan fungsi software pengolah kata Microsoft Office Power Point (MS Power Point)

2. Tutorial pengoperasian Microsoft Office Power Point (MS Power Point)

3. Praktek pengoperasian Microsoft Office Power Point (MS Power Point) oleh peserta pelatihan

Metode ini dipilih karena mengingat keterbatasan waktu, tenaga, dan dana yang tersedia.

\subsection{Rancangan Evaluasi}

Evaluasi diadakan di akhir acara, meliputi:

1. Pemberian tutorial kepada peserta pelatihan.

2. Praktek pengoperasian software pengolah kata Microsoft Office Power Point (MS Power Point) oleh peserta pelatihan, meliputi: (i) cara membuka, menyimpan dan menutup dokumen MS Power Point; (ii) cara penulisan dan pengaturan teks (iii) cara menyisipkan gambar; serta (iv) cara membuat tabel dalam MS Power Point.

3. Evaluasi dilakukan dengan melihat kerapian dan ketepatan pengaturan dokumen MW Word yang dilakukan oleh peserta pelatihan.

\section{IV.PEMBAHASAN}

\subsection{Pelaksanaan Pelatihan}

Pelaksanaan Pelatihan dilaksanakan di Masjid Al Mu'minun, Jl. Gilimanuk No. 64, serta di rumah salah seorang warga di wilayah RW-12 Kelurahan Lowokwaru Kota Malang. Materi Pelatihan diberikan dengan metode penjelasan dan praktek langsung. Pelaksanaan pelatihan ini dapat dilihat melalui dokumentasi kegiatan seperti pada gambar-gambar di bawah ini.

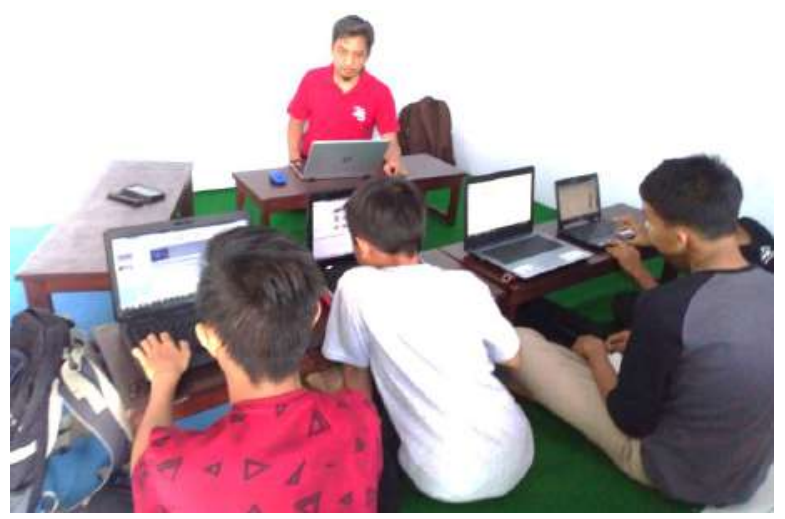

Gambar 1. Penjelasan Tentang Software Microsoft Power Point

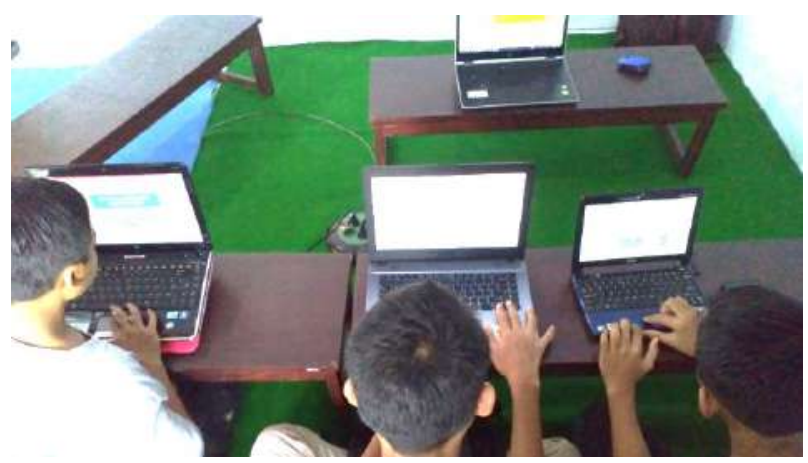

Gambar 2. Proses Pembuatan Slide pada Microsoft Power Point

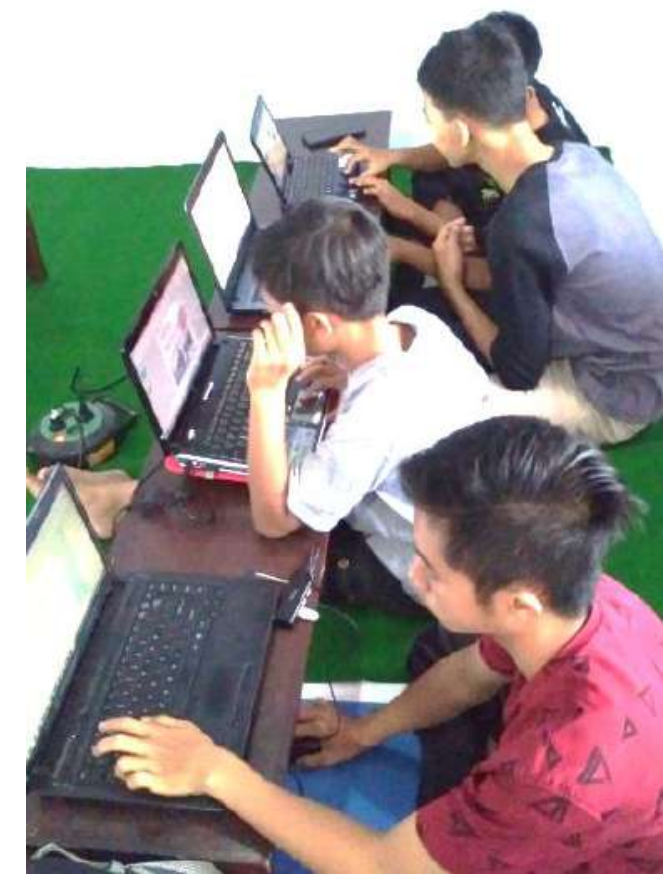

Gambar 3. Proses Insert Picture dan Video pada Microsoft Power Point 


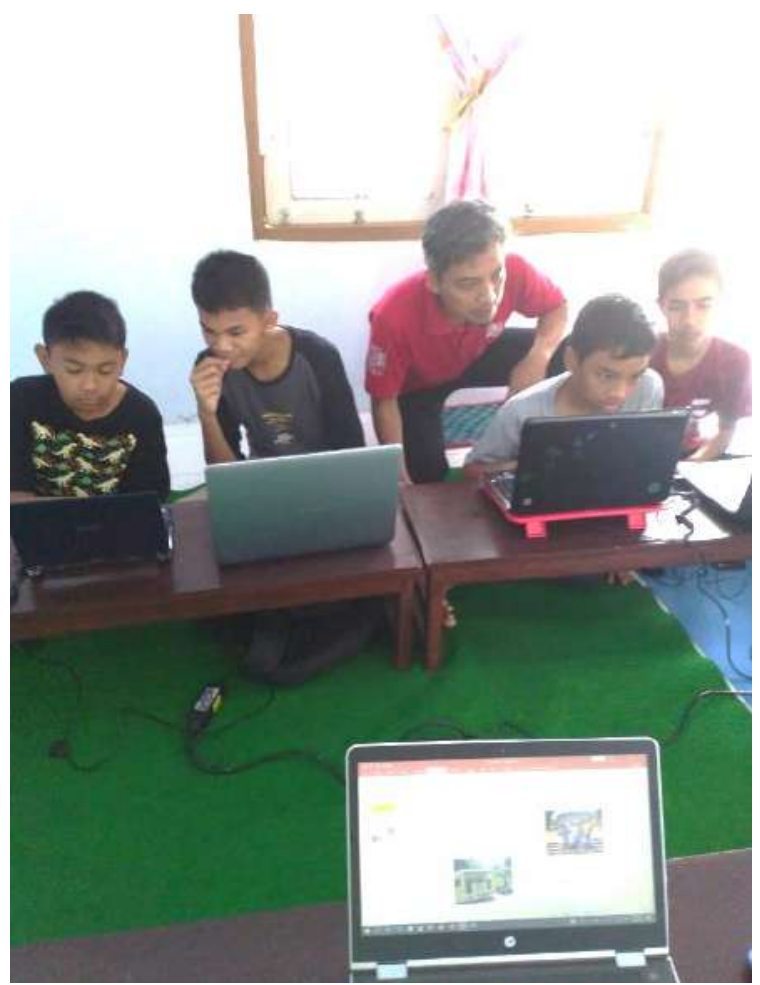

Gambar 4. Proses Penyelesaian File pada Microsoft Power Point

\subsection{Hasil dan Pembahasan}
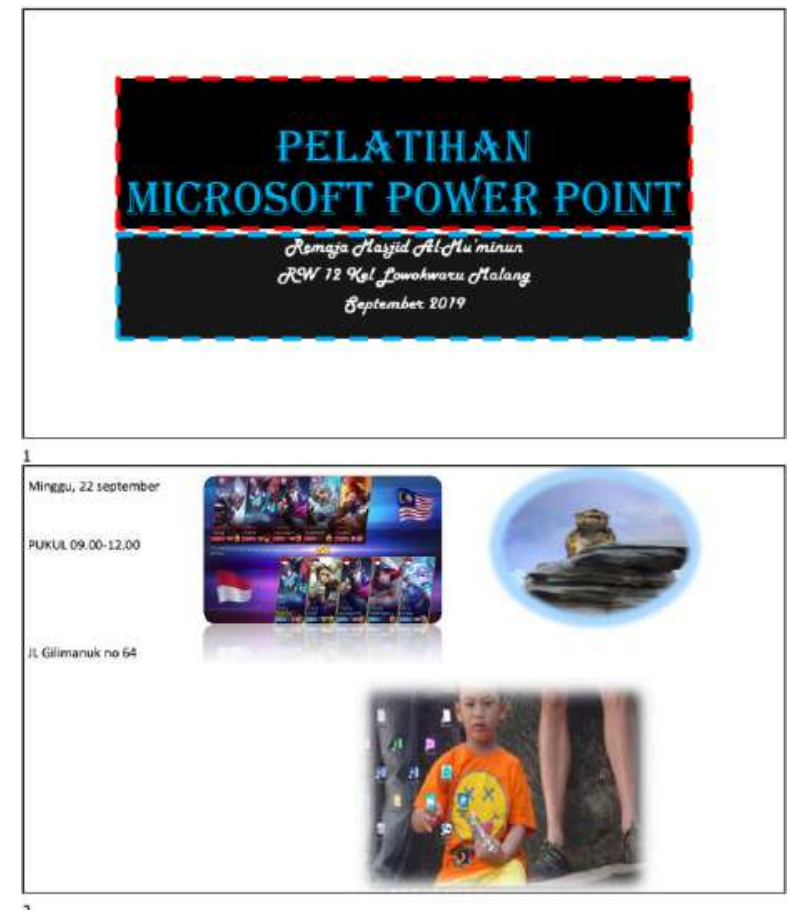

Gambar 5. Hasil Kerja Peserta dengan 2 Slide

Gambar 5 menunjukkan hasil kerja peserta, di mana peserta sudah dapat membuat file presentasi menggunakan Microsoft Power Point yang terdiri atas 2 slide. DI dalam file yang dibuat, peserta sudah mampu meng-insert dan meng-edit picture.
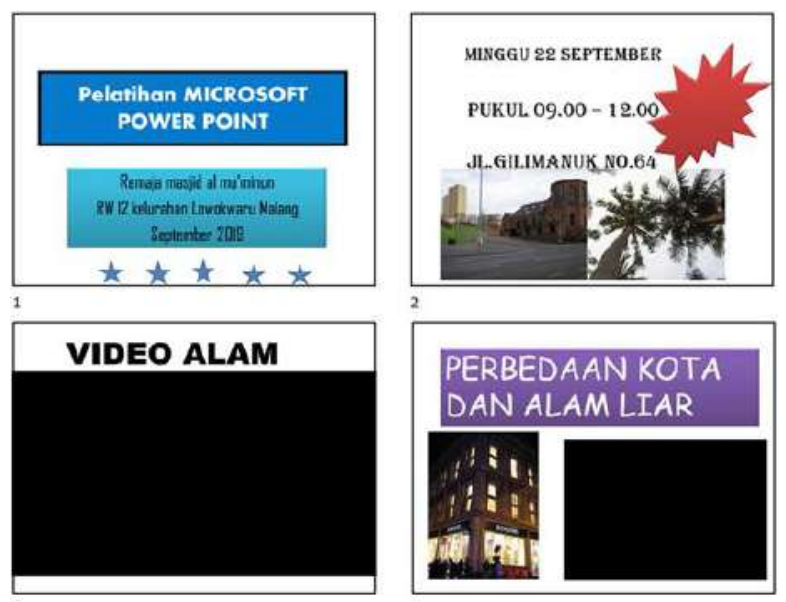

Gambar 5. Hasil Kerja Peserta dengan 4 Slide

Gambar 6 menunjukkan hasil kerja peserta, di mana peserta sudah dapat membuat file presentasi menggunakan Microsoft Power Point yang terdiri atas 4 slide. DI dalam file yang dibuat, peserta sudah mampu meng-insert dan meng-edit picture serta video.
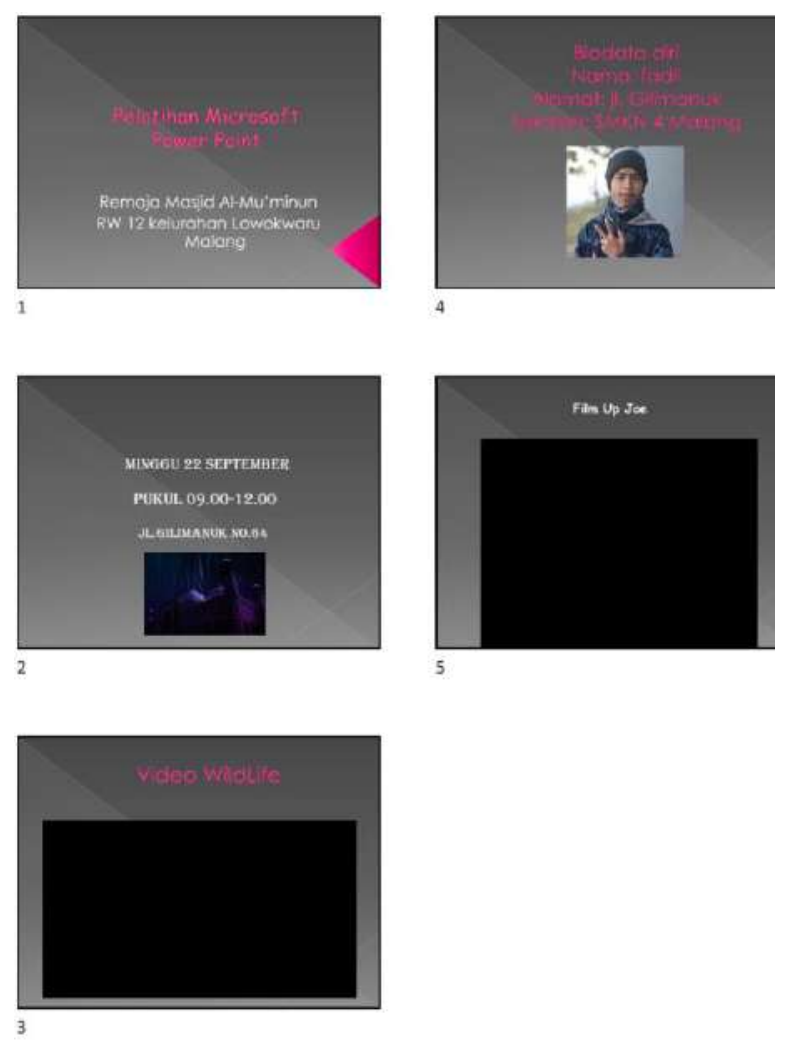

Gambar 7. Hasil Kerja Peserta dengan 5 Slide Gambar 7 menunjukkan hasil kerja peserta, di mana peserta sudah dapat membuat file presentasi menggunakan Microsoft Power Point yang terdiri atas 5 slide. DI dalam file yang dibuat, peserta sudah mampu meng-insert dan meng-edit picture serta video.

\section{V.KESIMPULAN DAN SARAN}

\subsection{Kesimpulan}

Setelah menelaah segala sesuatu yang berhubungan dengan aktivitas Pelatihan Microsoft Office Power Point pada Anak Usia Pendidikan Dasar di 
Lingkungan Masjid Al Mu'minun RW-12 Kelurahan Lowokwaru Kota Malang, maka dapat diambil kesimpulan yaitu :

1. Peserta memahami cara mengoperasikan software Microsoft Office Power Point sesuai dengan arahan yang diberikan selama pelatihan

2. Peserta berhasil membuat, menyimpan, serta mengedit file Microsoft Office Power Point

\subsection{Saran}

Perlu adanya tindak lanjut dari kegiatan ini, terutama dalam memberikan bimbingan dan dorongan kepada peserta pelatihan tentang manfaat dari Pelatihan Pelatihan Microsoft Office Power Point pada Anak Usia Pendidikan Dasar di Lingkungan Masjid Al Mu'minun RW-12 Kelurahan Lowokwaru Kota Malang

\section{DAFTAR PUSTAKA}

[1] Andrew Childress, Cara Cepat Membuat Presentasi PowerPoint Sederhana, https://business.tutsplus.com/id/tutorials/makesimple-powerpoint-presentations--cms-29269, diakses tanggal 22 Oktober 2018.

[2] Tugas dasar untuk membuat presentasi PowerPoint, https://support.office.com/id$\mathrm{id} /$ article/tugas-dasar-untuk-membuat-presentasipowerpoint-efbbc1cd-c5f1-4264-b48ec8a7b0334e36\#OfficeVersion=2007, diakses tanggal 22 Oktober 2018.

[3] Public Library, Intro to Microsoft PowerPoint. Burke County, USA, 2010.

[4] Anonymous. MS Power Point 2003.

[5] Centre for Educational Technology. Introduction to MS Power Point 2007. Cape Town: University of Capetown, 2009

[6] Montclair State University. Introduction to MS Power Point 2016. Montlair, USA, 2017. 